\title{
Introduction
}

\author{
John M Pinney
}

It gives me a great deal of pleasure to introduce Dr Michael McGinnis. He and I go back a number of years. Dr McGinnis is Assistant Surgeon General and Deputy Assistant Secretary for Health of the US Department of Health and Human Services. He chaired the 1977-78 Secretary's Task Force on Smoking and Health. Among his many contributions to disease prevention is the landmark Surgeon General's report on prevention, Healthy People. He and I shared the experience of developing reports under $\mathrm{Mr}$ Califano, who was Secretary at the time, and both of us, I think, can relate stories about being awakened late and early by $\mathrm{Mr}$ Califano or some of his minions wanting to know whether or not we were doing the job we were expected to do.

I think it's appropriate that the topic is the financing issues around smoking cessation. $\mathrm{Dr}$ McGinnis has been working for many years to integrate preventive services into all categories and channels of health care delivery, and I think we're at a very important moment in the health care reform effort. Decisions will soon be made about how health care will be structured and paid for and delivered, and clearly smoking cessation, at least most of us believe, has a rightful place in that scenario.

So it gives me great pleasure to introduce $\mathrm{Dr}$ Michael McGinnis to talk about financing issues. Thank you.

\section{Trends and issues in financing: payment for smoking cessation services}

\author{
J Michael McGinnis
}

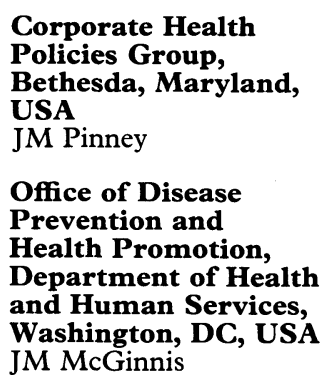

Impressive progress has been made in moving the tobacco issue to greater prominence on the health policy agenda. We are seeing renewed emphasis on tobacco education, greater commitment and tougher efforts to reduce access of minors to tobacco, more focus on the possible use of higher tobacco excise taxes, the classification this year by the US Environmental Protection Agency of environmental tobacco smoke as a Group A (known human) carcinogen, and the banning of smoking on the White House premises. These are welcome developments and hopeful harbingers of the prospects for future gains.

Nonetheless, smoking remains the leading cause of preventable death in the US. ${ }^{1}$ Despite gains that have been made since the release of the landmark Surgeon General's Report on Tobacco and Health in 1964, one in every five deaths is still attributable to tobacco, and even today tobacco use is practiced by more than one of every four adults. ${ }^{2}$ Moreover, trends show that increasing numbers of adolescents are beginning to smoke, with females and minorities disproportionately represented in these increases. ${ }^{3}$

Not only is the human cost of smoking high, but the economic costs of tobacco use are staggering. It has been estimated that the health consequences of tobacco use cost our country between $\$ 68$ and $\$ 72$ billion each year. ${ }^{4,5}$ While the national burden of tobacco use is so large as to be difficult to grasp, a more tangible way to look at the economic impact is through the fact that it averages out to a cost per smoker of approximately \$3-4 per day. Ironically, the groups for whom the least progress is being made in the campaign against smoking-women and African-Americans include those who can least afford the economic consequences.

Related to both individual and national costs of smoking are the trends and issues concerned with financing smoking cessation within our health care system. As of 1993, health care represents $14 \%$ of the gross domestic product - $\$ 3600$ on average for every man, woman, and child in the US. Provision of health care services to all Americans necessitates a sharper look at which services are truly effective, as well as at what mechanisms are available to deliver these services most efficiently. Consequently, to improve the efficiency with which health care is delivered, the pressure is tremendous for close scrutiny of services and their costs.

Despite the mandate for constraints on health care spending, there are positive signals 